HBHF_02_23763.

\section{Affect and Financial Decision-Making: How Neuroscience Can
Inform Market Participants \\ Affect and Financial Decision-Making: How Neuroscience Can
Inform Market Participants}

QUERY SHEET
Q1: Au: Please add Reference (from page 10

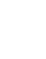

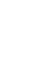

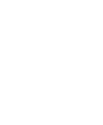

(n)

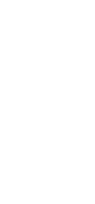

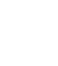




\title{
Affect and Financial Decision-Making: How Neuroscience Can Inform Market Participants
}

\author{
Richard L. Peterson, M.D.
}

\begin{abstract}
We review recent neuroscience literature on the influences of moods, attitudes, and emotions (affects) on financial decision-making. Evidence indicates the existence of separate brain systems, linked to affect processing, that are responsible for risk-taking and risk-avoiding behaviors in financial settings. Excessive activation or suppression of either system can lead to errors in investment choices and trading behaviors. We suggest ways for market participants to become aware of the potential impact of affect on their behavior in order to avoid suboptimal financial decisions. This paper has two overall aims: to educate financial practitioners about the origins of emotions that can adversely impact their performance, and to teach investors how to make better financial decisions.
\end{abstract}

keywords: Affect, Finance, Markets, Neuroscience, Decision

\section{Introduction}

15 investors systematically deviate from optimal trading behavior (Daniel, Hirshleifer, and Teoh [2002], Hirshleifer [2001], Odean and Barber [1998]). Some authors hypothesize that affect (emotions, moods,

20 feelings, and attitudes) plays a prominent role in financial decision making (see Lo and Repin [2002] and Lucey and Dowling [2005] for an excellent review). However, the mechanisms by which affect influences choice remain unclear. ${ }^{1}$

25 In this paper, we review the finance literature and assemble evidence that affect states influence both investor behavior and market prices. Using recent findings from neuroscience, we describe the neurological basis of affective influences on financial decisions. In

30 light of these new findings, we instruct readers how to manage disruptive affects as they arise in order to improve the quality of their financial choices.

To begin, consider the following paradox: Why do people buy both insurance and lottery tickets? Insurance, which insulates us from unanticipated financial losses, is an investment with negative expected returns. Buying lottery tickets is a gambling behavior that implies the acceptance of a negative expected return in the attempt to earn a larger gain. Ironically, we buy insurance to avoid potential losses, and we buy lottery tickets to pursue potential gains, yet both purchases

Richard L. Peterson, M.D. is a Managing Partner in Market Psychology Consulting Fairfax, California.

The corresponding author is Richard L. Peterson, Managing Partner Market Psychology Consulting, 399 Forrest Ave Fairfax, CA 94930 415.267.4880. Email: Richard@peterson.net Microsoft Word 2003 represent small expected losses. To explain further, we offer an explanation derived from understanding the brain's affective and motivational circuits.

Affect is defined as the subjective and immediate experience of emotion attached to ideas or objects (Sadock [2000]). Affect often has outward manifestations, such as altering normal facial expressions, vocal tones, and physical posture. Positive affect indicates optimism, and the evaluation of a decision based on potential gain. Positive affect motivates us to continue pursuing a course of action. Negative affect indicates pessimism, and the evaluation of a decision based on potential loss. Negative affect motivates us to avoid activities or situations that prompt it.

Affect states give rise to characteristic cognitive and behavioral tendencies. Risk-related biases in financial judgment have been associated with affect and named the "affect heuristic" (Slovic et al. [2002], Finucane, Peters, and Slovic [2003]).

Since Aristotle, scientists and philosophers have loosely hypothesized that two major brain functions are fundamental to almost all human behavior: reward approach (pleasure-seeking), and loss avoidance (pain avoidance) (Spencer [1880]). These systems can be activated or deactivated independently. When we face potential financial gains or losses, one or both of these systems may be used in decision making.

Neuroscience helps us understand the characteristics of these motivational systems and their consequences for our behavior. We review recent empirical evidence that shows the direct link between brain activation specific to these systems, affective states, and financial decision making.

The paper is organized as follows. The second section discusses the components of the reward and loss 
avoidance systems and defines affective states. The third and fourth sections survey empirical findings on the role of affect in financial markets and on trading beThe fifth section discusses some of the personal consequences of pathological disruptions in the functionality of these systems. The sixth section discusses the neurochemistry and genetics of risk assessment. The final section concludes, and proposes ways individuals can make better financial choices by taking into account the impact of affect on their decision making.

\section{Reward and Loss Avoidance Systems in Decisions under Risk}

Perceiving a potential reward in the environment sets the brain's reward approach system into action. Overall, the reward system coordinates the search for, evaluation of, and motivated pursuit of potential rewards. The neurons that carry information in the reward system transmit signals primarily via the neurotransof the five major dopamine pathways in the brain, the mesolimbic pathway, which extends from the ventral tegmental area (VTA) at the base of the brain, through the nucleus accumbens (NAcc) in the limbic system, to the gray matter of the frontal lobes (MPFC) (Bozarth [1994]) (see Figure 1).

Dopamine has historically been called the "pleasure" chemical of the brain. More recently, dopamine has been found to play a part in functions such as atten-
FIGURE 1

The Major Structural Components of the Reward System. The dopamine neuron cell bodies located in the ventral tegmental area (VTA) have axonal extensions through the nucleus accumbens (NAcc) and into the frontal lobes, including the medial prefrontal cortex (MPFC).

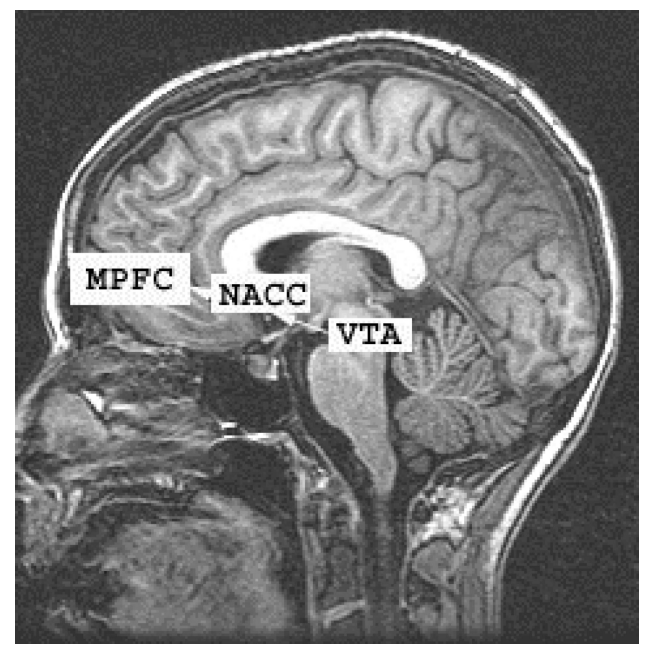

and pursuit. People who are electrically stimulated in brain regions with high concentrations of dopamine terminals report intense feelings of well-being (Heath [1964]). In fact, the dopaminergic pathways of the reward system are activated by illicit drug use, hence the 110 term "dope" to refer to street drugs. Dopamine activity in the reward system appears to correlate with subjective reports of positive affect (Knutson [2001b]).

The personality trait of extraversion is characterized by both reward-seeking and sociability (gregari- 115 ousness). Neuroscience researchers like Cohen et al. [2005] have found that activation of the brain's reward system is positively correlated with extraversion scores. Cohen et al. [2005] also found that the presence of the dopamine D2 receptor A1 allele correlates with extraversion and the strength of reward system activation when receiving financial rewards.

The brain's loss avoidance system is less defined than the reward system. It runs through several regions of the brain's limbic system, in particular the amygdala and the anterior insula. Its activity is mediated by serotonin and norepinephrine (among other neurotransmitters), and can be modulated with antidepressant medication such as selective serotonin reuptake inhibitors (SSRIs). Acute activation of the loss avoidance system can lead to the subjective experience and physiological signs of anxiety (Bechara, Damasio, and Damasio [2000])

Chronic activation of the loss avoidance system is indicated by the personality trait of neuroticism (Floury et al. [2004]), which is characterized by risk aversion. The prevalence of neuroticism has been weakly associated with the short form ("s"-allele) of the serotonin transporter gene, which leads to a decrease in serotonin sensitivity (Arnold, Zai, and Richter [2004]).

Amygdala activation appears to decrease when potential rewards are missed, showing an inverse correlation with punishment. The brain's insula is involved in the anticipation of aversive affective and noxious physical stimuli (Simmons et al. [2004]) and in selec- 145 tive disgust processing (Wright et al. [2004]). Paulus et al. [2003] show that insula activation is related to risk-averse decision making. They found that 1) insula activation was significantly stronger when subjects selected a "risky" response versus a "safe" response in 150 an experimental task, 2) the degree of insula activation was related to the probability of selecting a "safe" response following a punished response, and 3) the degree of insula activation was related to subjects' degree of harm avoidance and neuroticism as measured 155 by personality questionnaires.

Kuhnen and Knutson [2005] have demonstrated the roles of the reward and loss avoidance systems in portfolio choice and investment error. Their goals were to determine whether anticipatory brain activity 160 in the NAcc and anterior insula would predict riskseeking versus risk-averse choices, and whether acti- 
vating these regions would influence both suboptimal and optimal choices.

165 Kuhnen and Knutson's [2005] study combined a dynamic investment task with functional magnetic resonance imaging (fMRI). Subjects' actual investment choices during the task were compared to those of a rational risk-neutral agent who maximized expected

170 profit. Suboptimal choices were defined as deviations from this model, and included both "risk-seeking mistakes" (in which people take risks when they should not), and "risk-aversion mistakes" (in which people do not take risks when they should).

175 Kuhnen and Knutson [2005] found that while NAcc activation preceded both risky choices and risk-seeking mistakes, anterior insula activation preceded both riskless choices and risk aversion mistakes. These findings are consistent with the hypotheses that NAcc activation

180 represents gain prediction (Knutson et al. [2001b]), while anterior insula activation represents loss prediction (Paulus et al. [2003]). The results indicate that anticipatory neural activation contributes to rational choice and may also promote irrational choice. Thus,

185 financial decision-making requires recruiting distinct anticipatory mechanisms for taking or avoiding risks, while remembering that excessive activation of one mechanism or the other may lead to mistakes.

Overall, these findings suggest that risk-seeking

190 choices (such as gambling at a casino) and risk-averse choices (such as buying insurance) may be driven by two distinct neural mechanisms involving the NAcc and the anterior insula. The findings are consistent with the notion that activation in the NAcc and the

195 anterior insula relate to positive and negative anticipatory affective states, respectively. Activating one of these regions can lead to a shift in risk preferences. This may explain why casinos surround their guests with reward cues (i.e., inexpensive food, free liquor, surprise

200 gifts, potential jackpot prizes). Anticipating rewards activates the NAcc, which may lead to an increase in risk-seeking behavior.

\section{Affect in Market Pricing}

Over the past five years, several finance studies have 205 directly identified affective factors as likely causes of market price anomalies. Cloud cover, for example, has been used as a proxy for negative affect states (Schwartz [1983]). Hirshleifer and Shumway [2002] found that cloud cover in the city of a country's major

210 stock exchange was negatively correlated with daily stock index returns in eighteen of twenty-six national exchanges from 1982-1997. In New York City, there was a $24.8 \%$ annual return for all sunny days, and an $8.7 \%$ average return for cloudy days. The authors

215 cite psychology literature indicating that sunshine increases market participants' positive affect, and may thus collectively increase their willingness to accept risk.Kamstra, Kramer, and Levi [2001] find that stock returns are significantly related to season. They examine stock returns during the three months between 220 the fall equinox and the winter solstice, and the three months between the winter solstice and the spring equinox. The authors found that variations in the length of day contribute to stock returns. In particular, the market underperformed in the fall quarter and outper- 225 formed in the spring quarter. They hypothesize that affective shifts, like the seasonal mood variations of seasonal affective disorder, can alter risk preferences and subsequent investment behavior.

Krivelyova and Robotti [2003] found correlations 230 between strong geomagnetic storms and world stock market underperformance over the following six days. The authors noted that the psychology literature also demonstrates a correlation between geomagnetic storms and signs of depression in the general population over the two weeks following the storms. Depression is an affective disorder characterized, in part, by risk aversion.

Seasonal and meteorological factors may contribute to market price anomalies via collective changes in 240 affect (and thus risk preferences). However, the nature of these effects is still debated. Goetzmann and Zhu [2002] analyzed trading accounts of 79,995 investors from 1991 to 1996, and found that individual investors do not trade differently on sunny days versus cloudy 245 days. However, the authors did note that market maker behavior was significantly impacted by the degree of cloud cover. Wider bid/ask spreads on cloudy days were hypothesized to represent risk aversion among market makers.

If affect states do predict market price movements, how can we measure investors' average affect in order to predict market prices? In the finance literature, sentiment is the closest available measure. Both newsletter writers (Clarke and Statman [1998]) and individual 255 investors (Fisher and Statman [2000]) show increased optimism about future stock market gains (bullishness) following high recent returns. Additionally, Fisher and Statman [2000] found that as the S\&P 500 declined over a twelve-month period, investor optimism about 260 the stock market's future also declined.

Fisher and Statman [2000] noted that the percentage of investors who believed the market was overvalued was paradoxically correlated with expectations of future returns from 1998 to 2001. When investors 265 perceived the market as undervalued, they expected to earn lower returns. As sentiment became more optimistic or pessimistic in a positive feedback relationship with past price changes, so did expectations of future gains or losses. Additionally, sentiment levels 270 appear to be negatively correlated with (and somewhat predictive of) future market price changes (Fisher and Statman [2001]). 
Whether sentiment is a proxy for the activation of 275 the reward system (bullishness) or the loss avoidance system (bearishness) remains unknown. Positive feelings (like optimism) are a proxy for reward system activation, and it is very likely that the brain's motivational systems are engaged when forecasting future stock market gains or losses.

\section{Emotions and Personality in the Trading Pit}

Several researchers have investigated the psychological origins of successful and unsuccessful trading. Quantifiable differences have been found between the personality traits and emotional reactions of successfu versus less successful traders. Personality traits represent affective coping and impulse control strategies that differ from individual to individual. We previously discussed the personality trait neuroticism as a function of the loss avoidance system. The personality trait extraversion is correlated with optimism, an affect associated with reward system activation. Preliminary neuroscience evidence has suggested that extraverts have more sensitive reward systems during financial gain processing (Cohen et al. [2005]).

Lo and Repin [2002] took psychophysiological measurements from ten traders during real-time intraday trading and found that traders experienced physiological reactions during periods of market volatility.

300 They also showed that less experienced traders had significantly greater physiological reactions to market volatility than their more experienced colleagues. The authors concluded, "Contrary to the common belief that emotions have no place in rational financial

305 decision-making processes, physiological variables associated with the autonomic nervous system are highly correlated with market events even for highly experienced professional traders."

In a subsequent study, Lo, Repin, and Steenbarger

310 [2005] examined the trading patterns, personality characteristics, and daily affective reactions of eighty traders over twenty-five trading days. Only thirty-three of the traders completed the study, in part because of a $20 \%$ market decline during the study period. The au-

315 thors concluded that personality traits themselves are not important for trading. However, they did find a correlation between the strength of affective reactions and poor trading performance. They conclude, "Our results show that extreme emotional responses are apparently

320 counterproductive from the perspective of trading performance."

The big five personality traits - extraversion, conscientiousness, neuroticism, openness, and agreeableness - are directly related to styles of affective processing

325 and impulse control. Fenton-O'Creevy et al. [2004] conclude from a study of 118 professional traders at investment banks that successful traders tend to be emotionally stable, introverted, and open to new experiences.

Steenbarger [2003] performed personality tests on 330 sixty-four traders at a seminar conducted by "Market Wizard" Linda Bradford Raschke. He found that high conscientiousness scores (a measure of impulse control) were the most reliable predictor of trading success, but that high openness and high neuroticism were cor- 335 related with trading problems. He summarizes these findings as "one important lesson: Success in trading is related to the ability to stay consistent and plandriven." Emotional stability and impulse control tend to correlate with successful trading.

\section{Financial Decisions and Mental Health}

The neural origins of financial risk-taking can be partially understood by examining the underlying pathologies and treatments of individuals who exhibit disordered financial behavior. Some mental illnesses, 345 as defined by the Diagnostic and Statistical Manual IV-TR (American Psychiatric Association [2000]), result in abnormal financial behavior. Brain lesions in the orbitofrontal cortex, a processing center of the reward system, have been found to result in specific abnor- 350 malities in financial decision making (Damasio [1994], Shiv et al. [2005]). Taken together, these findings shed some light on the fundamental mechanisms of financial decision making.

Acute mania is a pathological mood state typically 355 characterized by euphoric mood and excessive risktaking (including with money). Some manic patients who have access to brokerage accounts will rapidly trade stocks, often until the account is drained. One website notes that some manic patients "go on shop- 360 ping sprees, spend food money to buy lotto tickets, or try to make a killing in the stock market" (Bernhardt [2005]).

Mania is caused by overactive dopaminergic circuits in the brain, including the mesolimbic circuit of 365 the reward system. Treatments for mania include antipsychotic medications that directly block or limit the neural stimulation caused by dopamine release. But these treatments are often rejected by patients because they also dampen the euphoric high that accompanies 370 an acute manic episode.

For another example, consider that the lifetime prevalence of pathological gambling disorder in the U.S. is less than $3.5 \%$ (American Psychiatric Association [2000]). Recent neuroimaging studies demonstrate 375 a hypoactivity of the reward circuitry in these individuals. Pathological gamblers often gamble to "feel excitement," which they achieve by activating their pathologically desensitized reward circuits.

Pathological gambling is often treated with naltrex- 380 one (Kim et al. [2001]), a medicine that blocks opiate 
receptors. In the reward system, mu opiate receptors stimulate dopamine release (Di Chiara and Imperato [1988]). Blocking opiate receptors with naltrexone de-

385 creases dopamine release in the nucleus accumbens, which results in decreased subjective feelings of pleasure (Jayaram-Lindstrom et al. [2004]). Gamblers taking naltrexone are not compelled to seek reward system stimulation through further gambling, possibly because they feel reduced pleasure from gambling.

Some subtypes of depression, such as "melancholic" depression, correlate with decreased dopamine activity in the reward pathway. Melancholic depression also correlates with anhedonia (lack of pleasure), ex-

395 cessive sleepiness, and chronic risk aversion, including in the financial markets.

One patient in treatment with this author for depression kept all her assets in cash. Because of her fear of financial risk, she was reluctant to invest in U.S. gov-

400 ernment bonds because she believed the government might default on payments. These thought distortions were directly related to her depressive illness and its neurochemical basis. Successful treatment with antidepressant medications was followed by small, tentative purchases of bonds and mutual funds.

The role of anxiety in biasing financial decisions is less clear-cut than for mania, pathological gambling, and depression. Pathological anxiety is characterized by exaggerated risk perception and hypervigilance. At

410 higher levels, anxiety may lead to panic and the psychophysiological "fight or flight" response (e.g., "panic selling"). Whether the "fight" or the "flight" response is triggered depends on past experiences, personality traits, anxiety intensity, and learned coping strategies.

415 Isolated mild anxiety leads to an overall reduction in risk-taking behaviors.

Anxiety can lead to either impulsive overtrading, or paralysis and avoidance of the markets. If the reward system is overactivated along with the loss avoidance

420 system, obsessive overtrading may result. If the reward system is underactivated, paralysis and passive anxiety may occur. Mild anxiety and neuroticism correlate with a paucity of serotonin function throughout the brain (Floury et al. [2004]). These disorders are

425 often successfully reversed with serotonin-enhancing medications like fluoxetine (Prozac).

Two mental disorders on the obsessive-compulsive spectrum merit discussion as well. First, compulsive shopping disorder is currently assumed to reside on

430 the obsessive-compulsive/anxiety spectrum of disorders, but its legitimacy as an independent mental illness is still being debated. Moderately successful treatment has been achieved with the SSRI antidepressant (citalopram) (Bullock and Koran [2003]). Second, the

435 disorder of hoarding, whereby sufferers accumulate excessive quantities of one type of good or asset, is also considered a subtype of obsessive-compulsive disorder. Only behavioral and psychotherapy approaches have shown success in treating hoarding (Saxena and Maidment [2004]).

\section{The Neurochemistry of Risk Assessment}

An article written by a psychiatrist in February 2000 was headlined "Is the Market on Prozac?" (Nesse [2000]). The article noted that prescriptions for psychoactive drugs increased from 131 million in 1988 to 445 233 million in 1998. The author went on to speculate, "I would not be surprised to learn that one in four large investors has used some kind of mood-altering drug." He also remarked that some of his patients on SSRI medications "report that they become far less cautious 450 than they were before, worrying too little about real dangers." He wondered whether the clear disregard for risk among many investors at that time was partly attributable to the use of common antidepressant medications.

In fact, many executives are rumored to refer to Prozac as the "teflon-medicine," because it allows them to look past perceived threats, decide quickly without ruminating, and remain more optimistic during stress. In his bestselling book, Listening to Prozac, psychia- 460 trist Peter Kramer [1993] frets about the potential use of SSRI antidepressants as "steroids for the business Olympics."

Knutson et al. [1998] gave normal subjects therapeutic doses of the antidepressant paroxetine (an 465 SSRI). Knutson's subjects experienced a reduction in threat perception and an increase in affiliative behaviors. In another study, subjects given the SSRI medication citalopram showed decreased amygdala (fearrelated) activations on fMRI (Del-Ben et al. [2005]). 470 The characteristics of decreased threat perception and increased social affiliation mirror the decreased risk perception and herding of excessively bullish investors. It is as if bubble investors are experiencing a partial deactivation of their brains' loss avoidance systems.

In addition, amphetamines are known to increase the brain's extracellular concentration of dopamine. Neuroimaging data collected by Knutson et al. [2004] suggest that amphetamines modulate dopamine signals in the NAcc area of the reward system. Anec- 480 dotal reports indicate that time-release amphetaminederived medications have been used by poker players to win millions of dollars in tournaments. "With Adderall [an amphetamine derivative] in my system, I am like an information sponge, able to process data 485 from several players at once while considering my next action" (Phillips [2005]). The author speculates that the increased focus and wakefulness promoted by amphetamines aids poker playing.

Some medications directly alter risk/return percep- 490 tions in behavioral experiments. Rogers et al. [2004] report that a common high blood pressure medication 
in the beta-blocker family decreased experimental subjects' discrimination of potential losses during a risky

495 task. "Propranolol [a beta-blocker] produced a selective change in volunteers' decision-making; namely, it significantly reduced the discrimination between large and small possible losses when the probability of winning was relatively low and the probability of losing 500 was high" (Rogers et al. [2004]). Propranolol is also one of the most common treatments for "stage fright," and is occasionally used to treat other types of anxiety and aggressive impulsivity.

Perhaps not surprisingly, other drugs have also been

505 shown to affect financial decisions. Lane et al. [2005a] designed an experiment in which subjects were given a choice between a certain low-value positive expected value option $(\$ 0.01)$ or a zero expected value option with high return variability (the risky option). THC-

510 intoxicated subjects preferred the risky option significantly more than control subjects who had been given a placebo. Additionally, if they lost money after selecting the risky option, THC-intoxicated subjects were significantly more likely to persist with it, while con-

515 trol subjects were more likely to move to the positive expected value option.

Lane et al. [2004] found a similar preference and persistence with the risky option in alcohol-intoxicated subjects when compared to controls. Deakin et al.

520 [2004] showed that a dose of the benzodiazepine valium increased the number of points wagered in a risktaking task in only those trials with the lowest odds of winning but the highest potential payoff. Lane et al. [2005b] found that administration of the benzodi-

525 azepine alprazolam produced increased selection of a risky option under laboratory conditions. The strength of subjects' risk-seeking personality traits may be predictive of how drugs affect their risk-taking behavior (Lane et al. [2005b]).

530 These studies illustrate that common chemical compounds can alter an individual's propensity for risk. In particular, frequently prescribed antidepressants and anxiolytics (SSRI medications) appear to decrease threat perception and increase social affili-

535 ation. Time-release amphetamines increase alertness and smooth the reward system's reactivity to potential financial gains. A common hypotensive medication (a beta-blocker) decreased aversion to potential financial losses. Findings regarding alcohol, marijuana, and ben-

540 zodiazepines suggest these drugs increase risky financial decision-making.

\section{How to Make Better Financial Choices}

\section{Trading Psychology}

The use of psychological techniques to improve per545 formance in the business world is increasing rapidly
(Goleman [1998]). For example, according to Schwager [2003], Steve Cohen, the principal of SAC Capital, is "unquestionably one of the world's greatest traders." SAC Capital has a former Olympic psychiatrist, Ari Kiev, M.D., on staff to assist traders in improving 550 performance. The use of a psychiatrist by one of the world's greatest traders certainly supports the notion that psychological management can benefit financial risk-takers. It may even suggest that people need psychological support to prevent themselves from suc- 555 cumbing to the most common cognitive, behavioral, and affective biases.

While observing Steve Cohen trade, Schwager [2003] is "struck by his casualness." Schwager notes, "He also seemed to maintain a constant sense of humor 560 while trading." Cohen's sense of humor and casualness demonstrate that he isn't taking his trading gains and losses "to heart." So how can the average financial decision maker maintain such an emotional balance and healthy state of mind?

One method of cultivating dispassion about financial performance is to maintain non-judgmental beliefs and flexible expectations. In particular, practitioners must realize that not every decision requires absolute perfection or they will invariably be disappointed. 570 George Soros [1995] provides an excellent example. Referring to his well-publicized philosophy, "belief in fallibility," he says, "To others, being wrong is a source of shame. To me, recognizing my mistakes is a source of pride. Once we realize that imperfect understand- 575 ing is the human condition, there's no shame in being wrong, only in failing to correct our mistakes."

Soros is thus protected from a crisis of confidence. For most people, the possibility of being wrong is threatening and can cause anxiety. As Cymbalista 580 [2003] notes, "The difference between Soros and most other traders is that he accepts fallibility, so he starts out by assuming his hypothesis is wrong, rather than right like almost everyone else." By maintaining a belief in fallibility, Soros remains open-minded about his 585 positions, and can minimize denial, disappointment, and anger if he learns his decisions were wrong.

\section{Investor, Heal Thyself}

Financial practitioners can improve their financial decision making by learning to interpret and man- 590 age affect states. With adequate self-awareness, affect states can be viewed as internal signals. As seen from the examples we cite here, investors are most likely to make subpar financial decisions if they are emotionally reactive or have poor impulse control. In either 595 case, a dysfunction of the reward or loss avoidance systems is likely to result. The affect states that can arise are conditioned by our past experiences, the vividness of the potential consequences, innate genetic endowments, and personality (among many other factors). As 600 
demonstrated in Kuhnen and Knutson [2005], strong affects threaten to override rational decision making and should be appropriately managed for optimal performance.

605 In clinical psychology, there are a plethora of strategies for regulating affect states. Use of these strategies may benefit financial practitioners who find themselves overwhelmed by affect (fear, euphoria, greed, panic, etc...) during their investment decision-making.

610 The first step in managing affects is to become aware of them. Biais et al. [2000] found that "highly selfmonitoring" traders perform better than their peers in an experimental market. While it is important to notice affect states, it is crucial to avoid placing any value

615 judgment on them. Judgments such as "I shouldn't be feeling this" or "I'm really good at this" interfere with the exercise and give rise to further affective reactions (annoyance, disgust, anger, frustration, and selfcongratulation, to name a few).

620 Some common causes of affective reactions among financial decision makers include the size of the potential reward or loss (Knutson et al. [2001b]), the vividness of potential consequences (Loewenstein et al. [2001]), and any counterfactual comparisons it rep-

625 resents (Mellers, Schwartz, and Ritov [1999]). Learn what financial situations cause affect to arise. Too often, affect is left unnoticed and unattended. Place the feelings in a context, and then practice noticing what automatic behaviors you associate with them.

630 Meditation, peaceful reflection, and contemplation are other disciplines that can be used to improve self-awareness. Financial practitioners should practice noticing the thoughts, feelings, and attitudes that underlie their decision-making. They can search for pat-

635 terns, relationships, and emotionality, impulsivity, or irritability in these thoughts and feelings. In particular, when observing greed and fear, ask yourself: "What causes this? Where did it come from? What is it related to?" By placing the affective information in a

640 personal context, you can become familiar with your "triggers" and use awareness of your emotional state to generate a personal warning signal. By understanding and contextualizing your emotions, you can more easily detect potentially weak decision situations when 645 they arise.

Self-discipline, a facet of the personality trait conscientiousness, relates to impulse management. It is essential to interrupting the automatic flow among emotions, thoughts, and behaviors. Self-disciplined people

650 are better able to control and channel their impulses toward goals. They can identify and delay acting upon their affects. To illustrate, we note that a survey of 600 foreign exchange traders in Europe and the U.K. by Oberlechner [2004] asked traders to rank the most im-

655 portant characteristics for professional success. From a list of twenty-three, "disciplined cooperation" ranked the highest.
Additionally, note that successful financial practitioners systematize as much of their decision-making as possible. Professionals are prepared for contingen- 660 cies, and they approach mistakes with curiosity, rather than dread, fear, or denial. As Lo and Repin [2002] find, experienced professionals are less reactive to market volatility than novices, which may be due to a classical conditioning process or their internal beliefs.

The brain's two motivational systems evaluate potential gains and losses independently. We are likely to experience relatively strong affects when one system is dominant and are prone to making irrational financial decisions. Our only clue to a personal condition of imbalanced motivational systems lies in our affect states. If we learn to become self-aware, we can perceive when one system is out of balance. Self-awareness, cultivating a "belief in fallibility," exercising techniques of affect management, and visualizing and practicing dif- 675 ficult decision situations can all assist in minimizing the irrational and costly impact of financial emotions. We can take action and learn to be more profitable.

\section{Conclusion}

Based on the research we summarize here, it is ap- 680 parent that recent financial gains and losses change investor behavior. Financial market participants need to monitor their own internal reactions to see how their decisions are biased by their recent experiences, and they must be careful not to let such biases affect deci- 685 sion discipline.

In particular, investors who have experienced a recent loss may note feelings of nervousness and/or other signs of irrational risk avoidance behavior like hesitation in entering new positions, excessive deliberation 690 about further potential losses, and seeing more financial threats than usual. They must take special care not to let that anxiety affect future discipline in trading decisions.

Conversely, investors who have recently earned 695 large gains may be feeling celebratory, extremely intelligent, or somewhat invincible. They must also make sure not to focus solely on potential returns and ignore the risk control and monitoring aspects required in making financial decisions.

Not everyone can maintain a disciplined investment strategy during the simultaneous gains or losses that accompany stock market fluctuations. Our research suggests that investors' undisciplined decisions may be biased in a way that furthers the development of bull 705 and bear markets. When the stock market is rising and most people are experiencing paper gains, many feel hypomanic, they ignore risks, and they overemphasize potential returns. Consequently, the market risk premium tends to decline and stocks rise further, gen- 710 erating more upward movements in the bull market. 
When the stock market is falling and most people are incurring paper losses, many become anxious, place more emphasis on the risky attributes of stocks, 715 increase the risk premium they require to invest in stocks, and abstain from buying. This allows the decline in stock prices to continue and a bear market to persist.

\section{Note}

720 1. Other research has examined the potential role of emotion in decision-making (Bernheim and Rangel [2004], Camerer, Loewenstein, and Prelec [2005], Loewenstein et al. [2001]). Also, economists have begun to incorporate emotion into models of individual choice (Bernheim and Rangel [2004], Caplin and Leahy [2001]). This research, however, did not focus on financial choices.

\section{References}

American Psychiatric Association (APA). Diagnostic and Statistical Manual of Mental Disorders, fourth edition, text revision (DSM-IV-TR), Washington, DC. (2000).

Arnold, P.D., G. Zai, and M.A. Richter, "Genetics of Anxiety Disorders." Current Psychiatry Reports, August, 6, 4, (2004) pp. 243-254.

Bechara, A., H. Damasio, and A.R. Damasio, "Emotion, Decision Making and the Orbitofrontal Cortex." Cerebral Cortex, March, 10, 3, (2000) pp. 295-307.

Bernhardt, Stephen L., "Bipolar Disorder: Tempering the Mania of Manic Depression." http://www.have-a-heart.com/bipolardepression.html, August 4 (2005).

740 Bernheim, D.B., and A. Rangel, "Addiction and Cue-Conditioned Cognitive Processes.” American Economic Review, 94, (2004) pp. 1558-1590.

Biais, B., D. Hilton, K. Mazurier, and S. Pouget, "Psychological Traits and Trading Strategies." Unpublished manuscript (2000).

745 Bozarth, M.A., "Pleasure Systems in the Brain." In D.M. Warburton, ed., Pleasure: The Politics and the Reality. New York: John Wiley \& Sons, (1994) pp. 5-14, references.

Bullock, K., and L. Koran, "Psychopharmacology of Compulsive Buying." Drugs of Today (Barcelona), September, 39, 9, (2003) pp. 695-700.

Camerer, C., G.F. Loewenstein, and D. Prelec, "Neuroeconomics: How Neuroscience Can Inform Economics." Journal of Economic Literature, 43 (2005).

Caplin, A., and J. Leahy, "Psychological Expected Utility Theory and Anticipatory Feelings." Quarterly Journal of Economics, 116, (2001) pp. 55-79.

Clarke, R., and M. Statman, "Bullish or Bearish?" Financial Analysts Journal, May/June, Vol. 54, No. 6, (1998) pp. 63-72.

Q1 Cohen and Ranganath [2004]. ).

760 Cohen, M.X., J. Young, J.M. Baek, C. Kessler, and C. Ranganath, "Individual Differences in Extraversion and Dopamine Genetics Predict Neural Reward Responses." Brain Res Cogn Brain Res. November, 10 EPub (2005).

Cymbalista, F., "George Soros: How He Knows What He Knows,

765 Part 1: The Belief in Fallibility.” Stocks, Futures, and Options, July, Vol. 2, No. 7, (2003).

Damasio, A., Descartes' Error: Emotion, Reason, and the Human Brain. New York: Avon Books (1994).

Daniel, K., D. Hirshleifer, and S.H. Teoh, "Investor Psychology in Capital Markets: Evidence and Policy Implications." Journal of Monetary Economics, 49, (2002) pp. 139-209.

Deakin, J.B., M.R. Aitken, J.H. Dowson, T.W. Robbins, and B.J. Sahakian, "Diazepam Produces Disinhibitory Cognitive Effects in Male Volunteers." Psychopharmacology (Berlin), April, 173, 1-2, (2004) pp. 88-97.

DeBondt, W., "Betting on Trends? Intuitive Forecasts of Financial Risk and Return." International Journal of Forecasting, November, Vol. 9, No. 3, (1993) pp. 355-371.

Del-Ben, C.M., J.F. Deakin, S. McKie, N.A. Delvai, S.R. Williams, R. Elliott, M. Dolan, and I.M. Anderson, "The Effect of Citalo- 780 pram Pretreatment on Neuronal Responses to Neuropsychological Tasks in Normal Volunteers: An fMRI Study." Neuropsychopharmacology, April 13 (2005).

Di Chiara, G., and A. Imperato, "Opposite Effects of Mu and Kappa Opiate Agonists on Dopamine Release in the Nucleus Accum- 785 bens and in the Dorsal Caudate of Freely Moving Rats." Journal of Pharmacology and Experimental Therapeutics, 244, (1988) pp. 1067-1080.

Fenton-O'Creevy, M., N. Nicholson, E. Soane, and P. Willman, Traders: Risks, Decisions, and Management in Financial Mar- 790 kets. Oxford, UK: Oxford University Press (2004).

Finucane, M.L., E. Peters, and P. Slovic, "Judgment and Decision Making: The Dance of Affect and Reason.” In S.L. Schneider and J. Shanteau, eds., Emerging Perspectives on Judgment and Decision Research. New York: Cambridge University Press, 795 (2003) pp. 327-364.

Fisher, K., and M. Statman, "Investor Sentiment and Stock Returns." Financial Analysts Journal, March/April, Vol. 56, No. 2, (2000) pp.16-24.

Fisher, K., and M. Statman, "Blowing Bubbles." Journal of Psychol- 800 ogy and Financial Markets, Vol. 3, No. 1, (2001) pp. 53-65.

Floury, J.D., S.B. Manuck, K.A. Matthews, and M.F. Muldoon, "Serotonergic Function in the Central Nervous System is Associated with Daily Ratings of Positive Mood." Psychiatry Res., November 30, 129, 1, (2004) pp. 11-19.

Goetzmann, W. and N. Zhu, "Rain or Shine: Where is the Weather Effect?," Yale ICF Working Paper No:02-27, (2002) www.ssrn.com

Goleman, D., Working with Emotional Intelligence. London: Bloomsbury (1998).

Heath, R.G., "Pleasure Response of Human Subjects to Direct Stimulation of the Brain: Physiologic and Psychodynamic Considerations." In R.G. Heath, ed., The Role of Pleasure in Human Behavior. New York: Hoeber, (1964) pp. 219-243.

Hirshleifer, D., "Investor Psychology and Asset Pricing." Journal of 815 Finance, 56, (2001) pp. 1533-1597.

Hirshleifer, D and T. Shumway, "Good Day Sunshine: Stock Returns and the Weather." Journal of Finance, June, (2002) pp. 10091032

Jayaram-Lindstrom, N., P. Wennberg, Y.L. Hurd, and J. Franck, 820 "Effects of Naltrexone on the Subjective Response to Amphetamine in Healthy Volunteers." Journal of Clinical Psychopharmacology, December, 24, 6, (2004) pp. 665669.

Kahn, H., and C.L. Cooper, "How Foreign Exchange Dealers in the 825 City of London Cope with Occupational Stress." International Journal of Stress Management, 3, (1996) pp. 137-145.

Kamstra, M., L. Kramer, and M. Levi, "Winter Blues: A SAD Stock Market Cycle.” American Economic Review, 1, (2001) pp. 324343.

Kim, S.W., J.E. Grant, D.E. Adson, and Y.C. Shin, "Double-Blind Naltrexone and Placebo Comparison Study in the Treatment of Pathological Gambling." Biological Psychiatry, June 1, 49, 11, (2001) pp. 914-921.

Knutson, B., C.S. Adams, G.W. Fong, and D. Hommer, “Anticipa- 835 tion of Monetary Reward Selectively Recruits Nucleus Accumbens." Journal of Neuroscience, 21, RC159 (2001a).

Knutson, B., J.M. Bjork, G.W. Fong, D.W. Hommer, V.S. Mattay, and D.R.R. Weinberger, "Amphetamine Modulates Human Incentive Processing." Neuron, 43, (2004) pp. 261- 840 269. 
Knutson, B., G.W. Fong, C.S. Adams, and D. Hommer, "Dissociation of Reward Anticipation versus Outcome with Event-Related FMRI." NeuroReport, 12, (2001b) pp. 3683-3687.

845 Knutson, B., O.M. Wolkowitz, S.W. Cole, T. Chan, E.A. Moore, R.C. Johnson, J. Terpstra, R.S. Turner, and V.I. Reus, "Selective Alteration of Personality and Social Behavior by Serotonergic Intervention." American Journal of Psychiatry, 155, (1998) pp. 373-379.

850 Kramer, P.D., Listening to Prozac: A Psychiatrist Explores Antidepressant Drugs and the Remaking of the Self. New York: Viking (1993).

Krivelyova, A., and C. Robotti, "Playing the Field: Geomagnetic Storms and International Stock Markets." Working paper, Federal Reserve Bank of Atlanta (2003).

Kuhnen, C.M., and B. Knutson, "The Neural Basis of Financial Risk-Taking." Neuron, 47, (2005) pp. 763-770.

Lane, S.D., D.R. Cherek, C.J. Pietras, and O.V. Tcheremissine, "Alcohol Effects on Human Risk Taking." Psychopharmacology (Berlin), February, 172, 1, (2004) pp. 68-77.

Lane, S.D., D.R. Cherek, O.V. Tcheremissine, L.M. Lieving, and C.J. Pietras, "Acute Marijuana Effects on Human Risk Taking." Neuropsychopharmacology, April, 30, 4, (2005a) pp. 800-809.

Lane, S.D., O.V. Tcheremissine, L.M. Lieving, S. Nouvion, and D.R. Cherek, "Acute Effects of Alprazolam on Risky Decision Making in Humans." Psychopharmacology (Berlin), April 14 (2005b).

Lo, A., and D. Repin, "The Psychophysiology of Real-Time Financial Risk Processing." Journal of Cognitive Neuroscience, 14, (2002) pp. 323-339.

Lo, A., D. Repin, and B. Steenbarger, "Fear and Greed in Financial Markets: A Clinical Study of Day-Traders." NBER working paper (2005).

Loewenstein, G.F., E.U. Weber, C.K. Hsee, and N. Welch, "Risk as Feelings." Psychological Bulletin, 2, (2001) pp. 267-286.

Lucas, R.E., and B.M. Baird, "Extraversion and Emotional Reactivity." Journal of Personality and Social Psychology, March, 86, 3, (2004) pp. 473-485.

Lucey, B.M., and M. Dowling, "The Role of Feelings in Investor

880 Decision-Making." Journal of Economic Surveys, April, Vol. 19, No. 2 (2005).

Mellers, B.A., A. Schwartz, and I. Ritov, "Emotion-Based Choice." Journal of Experimental Psychology, 128, (1999) pp. 332-345.

Mobbs, D., C.C. Hagan, E. Azim, V. Menon, and A.L. Reiss, . "Personality Predicts Activity in Reward and Emotional Regions Associated with Humor." Proceedings of the National Academy of Sciences, USA. November 8, 102, 45 (2005).

Nesse, R., "Is the Market on Prozac?" The Third Culture, online journal, February 28 (2000).

890 Oberlechner, T., "Perceptions of Successful Traders by Foreign Exchange Professionals." Journal of Behavioral Finance, Vol. 5, No. 1, (2004) pp. 23-31.

Odean, T., and B. Barber, "Are Investors Reluctant to Realize Their Losses?"' Journal of Finance, October, Vol. LIII, No. 5, (1998) pp. 1775-1798.

Paulus, M.P., J.S. Feinstein, G. Castillo, A.N. Simmons, and M.B. Stein, "Dose-Dependent Decrease of Activation in Bilateral Amygdala and Insula by Lorazepam During Emotion Processing." Archives of General Psychiatry, March, 62, 3, (2005) pp.
Paulus, M.P., C. Rogalsky, A. Simmons, J.S. Feinstein, and M.B. Stein, "Increased Activation in the Right Insula During RiskTaking Decision Making is Related to Harm Avoidance and Neuroticism." Neuroimage, August, 19, 4, (2003) pp. 14391448.

Phillips, P., "The 2005 World Series of Poker: How I Blew \$350,000. Plus: My Chemical Weapon, Modafinil.” Slate.com, July 7 (2005).

Reuter, J., T. Raedler, M. Rose, I. Hand, J. Glascher, and C. Buchel, "Pathological Gambling is Linked to Reduced Activation of the 910 Mesolimbic Reward System." Nature Neuroscience, February, 8, 2, (2005) pp. 147-148.

Rogers, R.D., M. Lancaster, J. Wakeley, and Z. Bhagwagar, "Effects of Beta-Adrenoceptor Blockade on Components of Human Decision-Making." Psychopharmacology (Berlin), March, 172, 2, (2004) pp. 157-164.

Sadock, B.J., "Signs and Symptoms in Psychiatry." In B.J. Sadock and V.A. Sadock, eds., Kaplan and Sadock's Comprehensive Textbook of Psychiatry, 7th ed. Philadelphia: Lippincott Williams and Wilkins, Vol. 1, (2000) pp. 677-688.

Saxena, S., and K.M. Maidment, "Treatment of Compulsive Hoarding." Journal of Clinical Psychology, November, 60, 11, (2004) pp. 1143-1154.

Schwager, J., Stock Market Wizards: Interviews with America's Top Traders. New York: Harper Business (2003).

Schwartz, N., "Mood, Misattribution, and Judgments of Well-Being: Informative and Directive Functions of Affect States." Journal of Personality and Social Psychology, 45, (1983) pp. 512 523.

Shiv, B., G. Loewenstein, A. Bechara, H. Damasio, and A.R. Dama- 930 sio, "Investment Behavior and the Negative Side of Emotion." Psychological Science, June, 16, 6, (2005) pp. 435-439.

Simmons, A., S.C. Matthews, M.B. Stein, and M.P. Paulus, "Anticipation of Emotionally Aversive Visual Stimuli Activates Right Insula." Neuroreport, October 5, 15, 14, (2004) pp. 2261- 935 2265.

Slovic, P., M. Finucane, E. Peters, and D.G. MacGregor, "The Affect Heuristic." In T. Gilovich, D.W. Griffin, and D. Kahneman, eds., Heuristics and Biases: The Psychology of Intuitive Judgment. New York: Cambridge University Press, (2002) pp. 397- 940 420.

Soros, G., Soros on Soros. New York: John Wiley \& Sons (1995).

Spencer, H., Principles of Psychology. New York: Appleton Press (1880).

Steenbarger, B., The Psychology of Trading. New York: John Wiley 945 $\&$ Sons (2003).

Trepel, C., C.R. Fox, and R.A. Poldrack, "Prospect Theory on the Brain? Toward a Cognitive Neuroscience of Decision under Risk." Brain Research: Cognitive Brain Research, April, 23, 1, (2005) pp. 34-50.

Willis-Owen, S.A., M.G. Turri, M.R. Munafo, P.G. Surtees, N.W. Wainwright, R.D. Brixey, and J. Flint, "The Serotonin Transporter Length Polymorphism, Neuroticism, and Depression: A Comprehensive Assessment of Association." Biological Psychiatry, July 13 (2005).

Wright, P., G. He, N.A. Shapira, W.K. Goodman, and Y. Liu, "Disgust and the Insula: fMRI Responses to Pictures of Mutilation and Contamination." Neuroreport, October 5, 15, 15, (2004) pp. 2347-2351. 